\title{
Evaluation Indexes and Modeling of Second Classroom of College Mathematics
}

\author{
Siyuan Chen, Fengjun Yan and Yuanchun Guo \\ Department of Foundation, Xian Siyuan University, Xian 710038, China
}

Keywords: College Mathematics; Second Classroom; Evaluation Index; Modeling

\begin{abstract}
From the current stage, setting up the second classroom in terms of college mathematics can not only play a supporting role, but also enhance the interaction between teachers and students through the use of instant messaging tools such as QQ and Wechat. It is no longer confined to the traditional infusion aching mode and provides students with more independent learning space, so that students can easily digest linear algebra, higher mathematics, probability theory and other knowledge, in order to achieve better learning results. However, in the process of setting up the second classroom, we should pay attention to establishing the second classroom evaluation index of college mathematics, and lay a good foundation for the second classroom reform practice.
\end{abstract}

\section{Introduction}

College mathematics involves a great deal of contents with a intense schedule and therefore, second classroom has gathered momentum in recent years. In this context, in order to strengthen the cultivation of students' classroom interest and creative thinking ability, the establishment of second classroom evaluation indicators in colleges mathematics should be completed, which should be in compliance with many scientific and systematic principles to carry out modeling too. Based on this, we can expect to perfect the second classroom while exploring and accomplish result of introducing bricks and jade. The quality of college mathematics teaching will be improved and a good academic atmosphere will be created to satisfy students' needs.

\section{The Influence of the Second Classroom of Mathematics on College Students}

The effect of mathematics second classroom on college students is mainly reflected in the following aspects: First, launching the second classroom in college mathematics can fully arouse students' interest in learning, change students' previous thoughts about boring class and ignite students' interest in mathematics and love mathematics from their heart based on abundant second classroom activities. Second, setting up the second classroom in college mathematics teaching can expand broaden students' horizon. The second classroom is an extension of classroom teaching, which tends to focus on the basic knowledge and theory of mathematics while second classroom will help to apply the knowledge into real problems to cultivate the ability of application. Thirdly, the second class of college mathematics facilitates the development of students' thinking ability, hands-on ability, and creative ability, so that the overall quality of students can be improved. For example, a school uses mathematics second classroom to organize a fun knowledge contest. In the first round of competition, it is mainly divided into mandatory questions, selective questions, answer race and risk questions, and they rise hands to answer based on 10 points for each answer. In the second round of competitions, each team will send a representative to pick the answer number and proceed to answer the questions. Each question has 10 points. In the third round of competitions, the four groups should follow the host's "start" instructions and answer the questions. After the three rounds of competition, the winning teams are selected. The organization of the second classroom activity has played a role in promoting the development of student quality.

In order to effectively exert the positive influence of the second mathematics classroom on college students, we should pay attention to the specific establishment and its modeling as well as the evaluation index 


\section{Specific Establishment of Evaluation Index and Modeling of Second Classroom for College Mathematics}

\section{Determine Evaluation Objects}

In order to give full play of the second classroom of college mathematics, we should pay attention to the establishment of its evaluation index and determine the evaluation objects. After the evaluation object is determined, it will be evaluated according to the evaluation objective and standard. This article evaluates the second classroom of college mathematics. From the service level, the author mainly evaluates the implementation of college education. From the perspective of service scope, this article mainly focuses on the second mathematics classroom evaluation. Education evaluation is a purposeful, planned, and organized activity. The main subjects of school education evaluation include teachers, students, leaders, parents, etc.

\section{Clear Design Principles}

In the specific establishment of the second class evaluation indicators for college mathematics in this study, the following design principles will be followed: First, the principle of science. That is to say, in the specific establishment of college mathematics second classroom evaluation indicators, efforts should be made to achieve consistency of indicators and goals, compatibility of indicators, and independence of indicators. Among them, the independence between the indicators refers to the idea that duplication and equivalent indicator is not allowed to avoid repeated scoring problems. Second, the principle of completeness. That is to say, when establishing the second classroom evaluation index, we should try best to ensure that the evaluation index can truly reflect the effects of in different stages, different levels, and different aspects, and fully understand the value of the second classroom education[1]. Third, the principle of rationality. That is to say, every evaluation index in the second classroom of college mathematics must be scientific and reasonable. It cannot be biased towards a certain learning stage or learning content, learning methods, etc. Instead, we should try to avoid arbitrariness and strive to give relatively fair evaluation results. Fourth, the principle of operability. In the course of establishing the second mathematics evaluation index, we have to guarantee the operability so as to help with the evaluation and give response in time which will further help to properly change the second classroom teaching activities and achieve better teaching results.

Establishment of Indicator System

The index system is the key to the second classroom evaluation of college mathematics. The basic assumptions of the indicator system in this article are as follows:

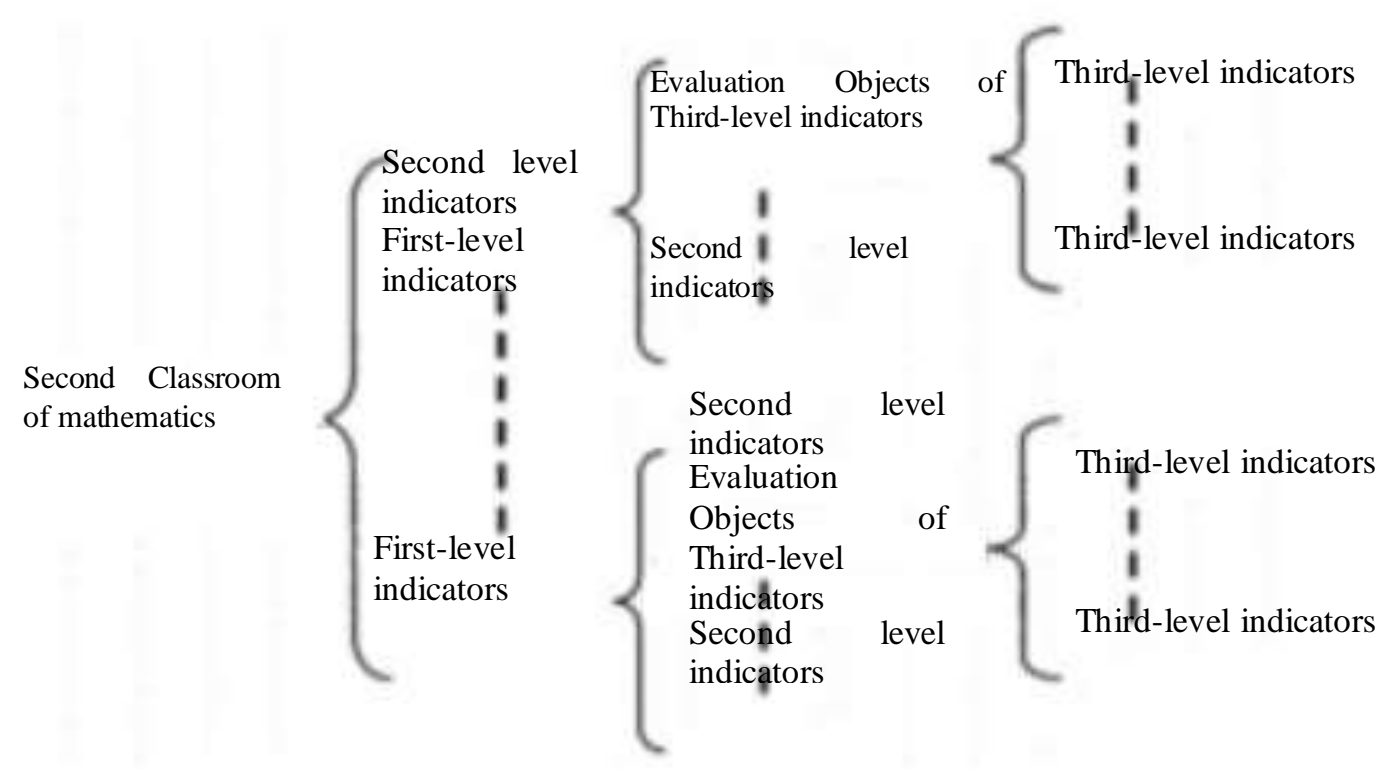

Figure 1 Basic design of indicator system 
For example, when a mathematics second classroom evaluation index system is established, a school improves the system content according to the basic assumptions of the index system. The school has established guidance for evaluation activities through the establishment of the second classroom evaluation index system for college mathematics, which has laid a good foundation for the evaluation work.

Establishing Evaluation Modeling

When the second classroom evaluation of college mathematics is carried out, it is necessary to pay attention to complete its evaluation modeling work in order to obtain better evaluation results. Taking a school as an example, we need to start from the following aspects:

First, according to the second classroom evaluation requirements of college mathematics, a hierarchical structure model was established as follows:

Second, each level weight is determined one by one according to the above hierarchy model. To begin with, when designing weights based on the total goal, the weights are set to $0.5,0.25$, and 0.25 respectively based on student evaluation, peer review, and expert evaluation. Next, construct a judgment matrix.

\begin{tabular}{ccccc}
\hline Index & $\mathrm{u} 1$ & $\mathrm{u} 2$ & $\mathrm{u} 3$ & Weight \\
$\mathrm{u} 1$ & 1 & 2 & 2 & 0.5 \\
$\mathrm{u} 2$ & $1 / 2$ & 1 & 1 & 0.25 \\
$\mathrm{u} 3$ & $1 / 2$ & 1 & 1 & 0.25 \\
\hline
\end{tabular}

After the determination matrix $\mathrm{A}$ is determined, the maximum eigenvalue of $\mathrm{A}$ is determined. The entire process is performed using MATLAB software.

Third, after the completion of the determination of the total target layer judgment matrix, the sub-target layer discriminant matrix design is performed.

\begin{tabular}{ccccc}
\hline Index & u35 & u36 & u37 & u38 \\
u35 & 1 & $1 / 5$ & $1 / 3$ & $1 / 3$ \\
u36 & 5 & 1 & 3 & 3 \\
u37 & 3 & $1 / 3$ & 1 & 1 \\
u38 & 3 & $1 / 3$ & 1 & 1 \\
\hline
\end{tabular}

The school adopts the mentioned analytic hierarchy process above to evaluate the status of the three teachers' mathematics activities in the second classroom. The results of the comprehensive evaluation are as follows.

\begin{tabular}{lllllllll}
\hline Index & $\mathrm{x}^{(\mathrm{k})} 2,1$ & $\mathrm{x}^{(\mathrm{k})} 2,2$ & $\mathrm{x}^{(\mathrm{k})} 2,3$ & $\mathrm{x}^{(\mathrm{k})} 2,4$ & $\mathrm{x}^{(\mathrm{k})}$ & $\mathrm{y}^{(\mathrm{k})}$ & $\mathrm{z}^{(\mathrm{k})}$ & $\mathrm{p}^{(\mathrm{k})}$ \\
Teacher1 & 94.66 & 92.65 & 91.23 & 92.66 & 92.37 & 90.32 & 90.70 & 91.44 \\
Teacher2 & 94.01 & 89.66 & 92.05 & 93.01 & 91.66 & 90.12 & 90.16 & 91.15 \\
Teacher3 & 92.32 & 91.66 & 91.02 & 92.01 & 91.58 & 90.43 & 90.50 & 91.02 \\
\hline
\end{tabular}

From the above evaluation results, it is learned that Teacher 1 has the best performance in the second classroom of college mathematics activities.

From the above cases, it can be seen that through the establishment of the second classroom evaluation model of college mathematics, we can actually see the result from a comprehensive perspective, which reflects its value and assistance for the first classroom [2]. Therefore, in the actual development of college mathematics teaching activities, we should deeply understand the importance of modeling, comply with the scientific, systematic, and operable principles to establish a second classroom evaluation model of college mathematics. It will be conducive to directing the implementation, improve the deficiencies and perfect the traditional classroom teaching.

Establishing Evaluation Criteria

In the course of establishing the second classroom evaluation index of college mathematics, attention should be paid to establishing the evaluation criteria and the following points should be accurately grasped. First, the standard intensity and frequency mainly refer to the degree of standard behavior required by the evaluation criteria. Second, labeling, application of 1, 2, 3 or A, B, C, etc. symbols mark the evaluation results of different standard intensities or frequencies. Third, the scale, which means that the unit of measure standard can be qualitative or quantitative.

When the second classroom evaluation standard for college mathematics is established, besides 
grasping the design of the above standard strengths, labels, and scales, the second classroom teaching thought and teaching reform practice must also be considered. At the same time, in the evaluation of the classroom, we should focus on the performance of the teacher's teaching literacy, and make judgments on the purpose and requirements of the teacher's teaching to see if there are related problems in the second classroom teaching [3]. Including "emphasizing teacher themselves, neglecting students", "re-instructing, ignore training", "concentrating on conclusions, and ignore the process", etc., in order to maximize the value of education through a all-round investigation of second classroom mathematics. Based on this, we can improve the quality of college mathematics classroom teaching. It is of pivotal importance to do the second classroom evaluation index and modeling during teaching, and we should always attach great attention to this issue.

\section{Conclusion}

In summary, it can be seen that the teaching mode based on classroom teaching is not conducive to the development of students' innovative thinking ability, and it is difficult to mobilize students' positive learning emotions. At the same time, the teaching effect is not ideal. In this context, attention should be paid to the secondary classroom teaching aids to make up for the deficiencies in college mathematics classroom teaching. In addition, the author proposes that in the process of establishing the second classroom of college mathematics, it is necessary to complete the second classroom evaluation index establishment and modeling by determining the evaluation object, clarifying the design principles, establishing the index system, establishing the index weight, establishing the evaluation criteria, and so on. This will further enhance the second classroom teaching level in college mathematics and achieve better teaching results.

\section{References}

[1] Chen Siyuan, Guo Yuanchun, Yan Fengjun. Analysis of the second classroom instructional ideology and teaching methods in college mathematics. Henan Education (Higher Education), August 20, 2017, No. 08: 88-89.

[2] Song Yanping. The Design of the Second Classroom Study Model of Advanced Mathematics Based on the WeChat Platform-Taking Xinjiang Agricultural University as an Example. Academy, February 25, 2017, No. 06: 10-11+27.

[3] Zhang Zhijuan, Nie Dayong. The application practice and thought of carrying out second classroom teaching in college mathematics . Education and Teaching Forum, January 21, 2015, No. 03:191-192.

[4] Yu D, Peng L. When does Inferring Reputation Probability Countervail Temptation in Cooperative Behaviors for the Prisoners' Dilemma Game? [J]. Chaos, Solitons \& Fractals, 2015, 78: $238-244$. 